\title{
Effect of Organizational Change on Employee Job Involvement: Mediating Role of Communication, Emotions and Psychological Contract
}

\author{
${ }^{*}$ Arfan Khalid 1 , Rana Rashid Rehman² \\ ${ }^{1}$ COMSATS Institute of Information Technology, Islamabad, Pakistan \\ ${ }^{2}$ Quaid-i-Azam University, Islamabad, Pakistan \\ *arfankhalid86@yahoo.com
}

\begin{abstract}
The purpose of the current paper is to provide a conceptual framework for studying the impact of organizational change on employee job involvement while communication, emotions and psychological contract plays mediating role in this relationship. The current study conceptualize that organizational change followed by effective communication generate the positive emotions which ultimately increase the employee job involvement where as organizational change with ineffective communication causes negative emotions which results in low employee job involvement. The study also founds that organizational change may break the psychological contract between employee and employer which reduces the employee job involvement.
\end{abstract}

Key Words: Organizational change, emotions, communication, employee job involvement.

\section{Introduction}

The hallmark of any learning organization is change. Organizations implement change in order to compete in the competitive environment. Organizations that do not change with the passage of time, their survival is at stake. The current paper discuss the effect of organizational change both at micro (mergers, acquisitions, downsizing and privatization) and macro level on employee's job involvement. (Kohler, Munz, \& Grawitch, 2006) argues that when there is change in the organization, it has impact on employee's job involvement. Since, there is no single definition of employee job involvement because different researcher has defined job involvement differently regarding their field of study or scope of their study. Uygur \& Kilic (2009) defined job involvement as motivation to do work and it is high degree of compatibility between personal and organizational goals, which provides motivation to the employee to produce positive work outcomes. Li Mei \& Hung (2008) define job involvement as fulfillment of one's cognitive needs, which helps him to work harder and improve his performance. Job involvement consists of personal and environmental factors, some researcher state that environmental factors can better predict job involvement, whereas other researchers considers personal attributes more relevant to predict job involvement (Liao, \& Lee, 2009). In effect, both factors constitute job involvement. When organizational change is considered as challenge then it triggers positive response and when it is considered as threat then it triggers negative response. In case of threat, change has impact on employee's perception of job insecurity, anxiety and depression (Conner, 1993). And in case of challenge, change has impact on motivation, loyalty, job commitment and job satisfaction (Reichers, Wanous \& Austin, 1997). So organizations need to develop sense of challenge in their employees in order to get positive response of change and in order to avoid dissatisfaction and depression among the employees.

As, Howard (2006) argues that "Emotions help us to deal with challenges and threats, set new goals, learn new behavior and draw on others for help. They excite our interests, focus our attention, alert us to the need for change and move us to act." There are basically two types of emotions; Positive and negative emotions, positive emotions have positive impact on cognition and performance and negative emotions have adverse effect on thoughts and behavior (Dyck, Caron, \& Aron, 2006) which in turn effects the employee job involvement. However, the generation of favorable emotions and creating the challenging environment for employees can only possible through effective communication where as ineffective communication during organizational change period may result in unfavorable emotions and trigger threatening environment. Organizational change may also result in the breakage of psychological bonding between employer/workplace and employee which can reduce the employee job involvement. The current study 
throws light on how organizational change effects employee job involvement and how communication, emotions and psychological contract can play mediating role during organizational change to effect the employee job involvement?

\section{Literature Review and Theoretical Framework}

Organizational change, ineffective communication and negative emotions: Organizational change is defined as the challenge to the way things are normally done in an organization, and as a result individuals feel uncertainty, stress and fears about the potential failure of meeting the new situation (Vakola \& Nikolaou, 2005). Organization change is also defined as intentionally generated response to environmental shift (Jimmieson, Terry \& Callan, 2004). Organizations adopt change in order to remain competitive in the market, for that they need competitive strategies like mergers, acquisitions and downsizing and these competitive strategies has negative impact on employees (Shook \& Roth, 2011). Researchers have found that organizational change is different than the Lewin's unfreezing-moving-refreezing model (Lewin, 1947) because in reality it is difficult for the employees to reach refreezing state due to uncertainty and stress. This uncertainty and stress is overcome by effective communication but absence of effective communication can increase the amount of stress and uncertainty. Lack of communication creates feelings of threat, uncertainty, alienation and anxiety, resulting in increased workplace stress, and increased levels of absenteeism and turnover (Erturk, 2008). Lack of communication also creates ambiguity in the minds of the employees due to the rational thinking of the employees and some outside interventions, perhaps the managers (Randall \& Procter, 2008). Sometimes employees have ambiguity and uncertainty in their minds due to fear about the outcomes and sometimes manager's interventions are not timely and meaningful.

As a result of organizational change, there might be mismatch and incompatibility between employee's personal and organizational goals. Employees might not be sure about their roles in the organization due to ineffective communication during the change process or lack of communication climate during organizational change, which can cause role ambiguity, role conflict and interpersonal conflicts, collectively theses are known as job stressors (Suzy, 2001). These job stressors produce negative emotional reactions such as stress and anxiety. Strain is the ultimate outcome of job stressors; there might be psychological strain in form of job dissatisfaction and turnover intentions, physical strain in form of headache and increased blood pressure and behavioral strain in form of smoking and withdrawal from work (Suzy, 2001). The behavioral part strain is also regarded as counterproductive work behavior that means an employee can show counterproductive work behavior after the major change in the organization. So, collectively we can regard job stressors as negative emotions as they create fear in the minds of employees about the outcomes. Howard (2006) defines negative emotions as present reality, fears, shortfall and pessimism that constitute what we are in everyday life. So emotional reactions produced after the change process (uncertainty, stress and anxiety) and job stressors are regarded as negative emotions because these are related with current fears and shortfalls.

P1: Negative emotions are created during organizational change due to ineffective communication.

This conceptual paper discusses the refreezing phase of Lewin's model with the perspective of individuals in the organizations that how change effects individuals in terms of their attachment to the previous workplace before organizational change and their job involvement after organizational change. So, during organizational change, ineffective communication can produce negative emotions in the minds of employees, which can reduce their job involvement. Because when employees are having fears in their minds regarding uncertainty, job insecurity and job stressors are present here, so employees can be de-motivated to do their jobs. As Uygur \& Kilic (2009) defined job involvement as motivation to do work, due to presence of negative emotions employee's motivation to do their routine work is badly affected. Consequently, in this way we can say that employee job involvement decreases.

P2: There is a negative relationship between negative emotions and employee job involvement.

Organizational change, psychological contract and employee job involvement: Another important aspect during organizational change is place attachment. Place attachment is defined as multi level personplace bond that is developed through specifiable conditions of the place and characteristics of the people 
(Inalhan, 2009). Workplace attachment is also defined as the existence of emotional bond between an individual and an organization as a result of interactions in organizational setting (Milligan, 1998; Milligan, 2003). So when organizational change happens, organizational setting changes and it breaks the bond between employees and workplace and can possibly reduce employee job involvement. This is the kind of attachment of employees with the workplace, which is developed over the period of time. Similar is the case of management change during organizational change; the expectation of management regarding the perceived level of output and employee expectation regarding their rewards also changes. These expectations present in the mind of management as well as in the mind of employees are regarded as psychological contract between employee and employer. Psychological contracts consist of two dimensions, i.e. employeefocused and employer-focused obligations, both with the perspective of employees (Schalk, Campbell, \& Freese, 1998). Sometimes incompatibility occurs between these two dimensions as a result of organizational change, which can create dissatisfaction in the minds of employees and can result in reduced level of job involvement.

P3: Organization change breaks the psychological contract between employee and employer, which reduces their job involvement,

Organizational change, effective communication and positive emotions: Communication plays an important role in effective change management. The most commonly used approach for effective communication during organizational change is multiplier approach. The essence of the multiplier approach is to prepare employees from different units and levels to play a central role in communication relating to a specific change. A multiplier approach is particularly appropriate when a change affects several elements of an organization (e.g. strategy, structure, systems and/or processes), and when a change requires communication to a large number of employees at different locations over a long period of time (Wagner, 2008). Organizations are formed and run by people, some of these are noticed in the organization and visible to public and some of these are not visible to public and unnoticed in the organization, they work behind the scenes. But when change occurs in an organization these unnoticed and invisible people become major victim of the change process. For many of these people change results in loss of job, early retirement, change of career or they become victim of downsizing. Therefore, in order to avoid these negative feelings internal communication plays an important role (Proctor, \& Doukakis, 2003).

Elving (2005) discussed about creating a community in the organization through communication in order to build trust in the organization, increase commitment in the organization and increased readiness for change with the perspective of providing support to the change process. In fact communication is not limited to the unfreezing and change phase of the lewin's model, it can be applied to the refreezing phase of the lewin's model in such a way that communication can play its role in decreasing the uncertainty, job insecurity, fear and stress. Collectively we can say that communication can play a mediating role in increasing the employee job involvement after the organizational change. Organizations with high level of uncertainty need to increase the amount of information to the employees in order to decrease uncertainty (Kirsch, Chelliah \& Parry, 2011).

Communication plays vital role in any organization in civilizing or improving employee-employer relationship. Receptivity of employees to organizational change is an emerging and significant issue for those involved in creating successful change implementation strategies. Avoiding problems associated with change fatigue and change resistance are important considerations given ongoing agendas for change in contemporary organizations. Frahm \& Brown (2007) in their research paper argued that organizational change communication is a crucial element in employees' receptivity to change and accordingly, use an organizational change communication lens to map and analyze organizational change in the organization. A recent call for empirical studies in relation to organizations engaged in continuous change and change receptivity (Pettigrew, Woodman, \& Cameron, 2001), highlights the importance of undertaking further research in this area. Effective communication is very important when going for change.

Relationship between change and communication is widely studied over last few decades. Almost every one argued the same, scholars have stated that communication and change is a subject field that is very important to develop in order to get positive results (Jones, Watson, Gardner, \& Gallois, 2004; Taylo, Flanagin, Cheney, \& 
Seibold, 2001). Concerning the importance of effective communication it allows organizational employees to develop their identities, deal with anxieties (Gabriel, 2000) and make sense of incoherence and uncertainty (Weick, 1995). Sense making, or the creation of meaning, is a demonstration narrative process (Weick, 2001) that satisfies the fundamental human need for meaning and affects a person's identities (Weick, 2001). It also allows organizational employees to reconcile violated beliefs and to establish purpose, control and self-worth (Sommer \& Baumeister, 1998).

Little is currently known about the dynamics of positive emotions like motivation and organizational loyalty development at the workplace under conditions of change. This is problematic because personal preferences can affect organizational behavior and success through effective communication (Gioia, Schultz, \& Corley, 2000). The reflexive changes in personal emotions have far-reaching implications (Archer, 2007) on organizational employees and on the wider organization through processes of job involvement. According to Brutus \& Greguras (2008) effective communications leads towards positive motivation of employees and hence increase loyalty. Howard (2006) defined positive emotions as personal dreams, hopes, optimism and self-directed learning goals that shape our behavior in such a way that we are motivated to achieve what we want to become.

P4: Organizational change effects the emotions of employees positively if it is communicated well.

Positive emotions and job involvement: As it is said that motivation and attitudes play an important role in determining learning effectiveness (Noe, 1986), identifying factors that have strong influence on learning motivation is of high interest to both academics and practitioners. Job involvement is proposed as having such influence. Job involvement is defined as the extent to which individuals identify psychologically with work or the importance of work to the total self-image (Lodahl, \& Kejner, 1965). Job involvement is conceptualized as a cognitive state of psychological identification with the job which, in turn, depends on the need-satisfying potentialities of the job (Kanungo, 1982). Within the organization culture effective communication plays very important role in developing positive emotions like motivation and loyalty of employees which leads to job involvement. Therefore, employee' motivation to improve job-related skills affects the extent to which they are involved in their jobs (Noe, 1986). In other words, employees who are communicated well and are highly motivated are more likely to have high level of job involvement. This is because they have adequate knowhow of their surroundings and they know how and what to do (Noe, 1986). Noe \& Schmitt (1986) found that highly job-involved trainees are more motivated to learn and transfer the skills to the job because they are communicated well. Facteau, Dobbins, \& Russell, et al. (1995) also found that the variation in motivation level is significantly explained by individuals' job involvement. Thus, in the current study, motivation and loyalty are hypothesized to predict job involvement of employee positively.

P5: High level of motivation and loyalty is positively related to job involvement of employees.

On the basis of above literature review, we propose the following conceptual model for organizational change and employee job involvement along with the mediating role of communication, emotions and psychological contract.

Figure 1: Proposed Conceptual model

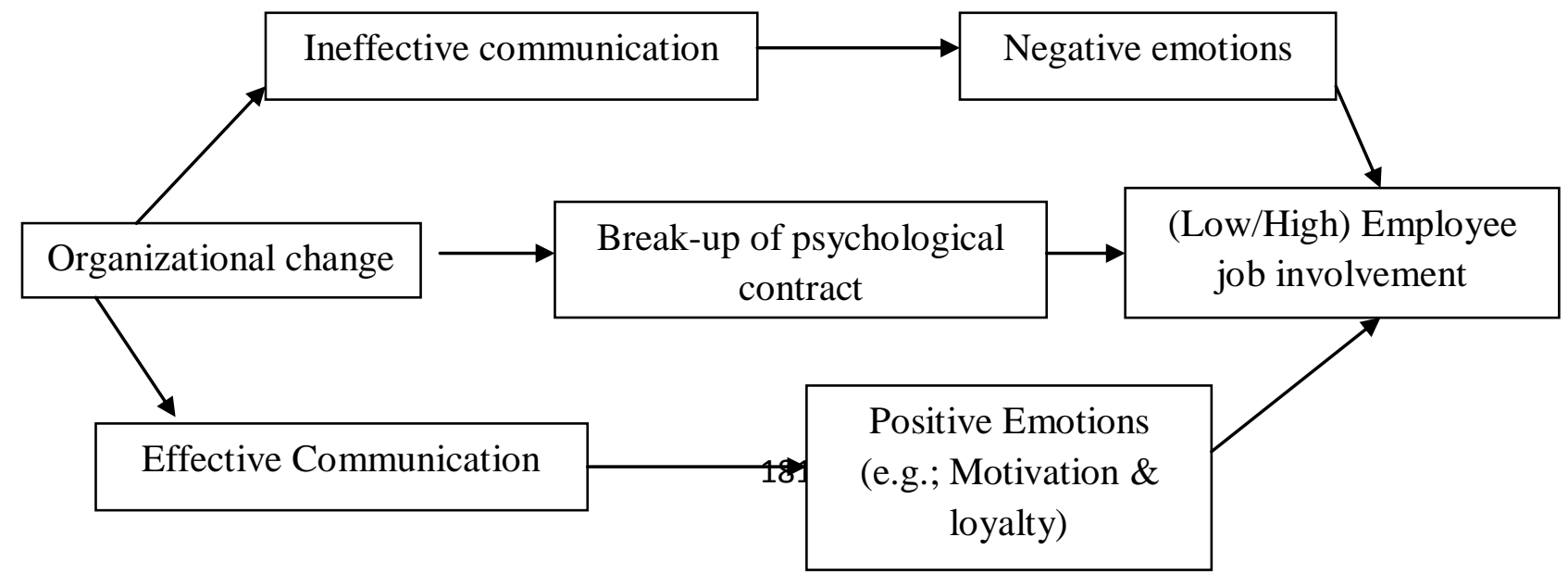




\section{Discussion}

In this research paper a conceptual model is presented in order to measure the impact of organizational change on employee job involvement while communication, emotions and break-up of psychological contract play the mediating roles. The current study proposes the framework about understanding the emotions after organizational change and role of communication in shaping the emotions towards job involvement. There has been a lot of discussion regarding role of communication in effective organizational change. But little discussion on role of communication after organizational change, that is through communication organization can build consensus within the organization about the change but communication is also important after the change, as it will decrease role ambiguity, role conflicts and interpersonal conflicts (Suzy, 2001). During the post-change phase of organizational change, communication plays a vital role in the determination of the emotions of employees as organizational change leads towards the generation of positive emotions if it is communicated effectively while ineffective communication causes the generation of negative emotions which ultimately affect the employee job involvement. Employees with positive emotions have high level of employee job involvement while employees with negative emotions have low level of job involvement due to anxiety, depression and counterproductive work behavior (Erturk, 2008). The current study also conceptualizes that organizational change may result in the breaking of psychological contract between employee and employer that also cause in the reduction of employee job involvement because when organizational change happens, organizational setting changes and it breaks the connection between employees and workplace and can possibly decrease the employee job involvement.

\section{Conclusion and Recommendations}

The current study proposes the relationship between organizational change and job involvement while communication, emotions and psychological contract play the mediating roles. Study founds that organizational change followed by effective communication, produce the positive emotions which ultimately increase the employee job involvement where as organizational change with ineffective communication causes negative emotions which results in low employee job involvement. Study further founds that psychological contract plays the mediating role between the relationship between organizational change and job involvement.

The researchers in future can use this conceptual model to empirically check the strength of proposed relationships between the organizational change and employee job involvement. There has been a lot of work done on the pre-change phase and role of communication in making change happen in the organization. The practitioners can use this model in order to focus on post-change phase and helpful for the practitioners to concentrate on the after change aspects in order to increase employee job involvement and productivity. This paper highlights the way change is perceived by the employees, some recognize it as a threat and other recognize it as challenge. By effective communication, goals of the change process and making sense of the change process can be incorporated with the perspective of building consensus within organization and ensuring increased level of employee job involvement. It is noted that negative emotions will occur but it depends on individuals that how the cope with those negative emotions. There is need for the practitioners to take account of negative emotions and devise active strategies to support individual to cope with it.

\section{References}

Archer, M. S. (2007). Making our way through the world: Human reflexivity and social mobility, Cambridge University Press.

Brutus, S. \& Greguras, G. J. (2008). Self-construals, motivation and feedback-seeking behaviors. International Journal of Selection and Assessment, 16, 282-291.

Conner, R. D. (1993). Managing at the speed of change. Villard Books.

Dyck, L. R., Caron, A. \& Aron, D. (2006). Working on positive emotional attractor through training in health care. Journal of Management Development, 25(7), 671-688.

Erturk, A. (2008). A trust-based approach to promote employees' openness to organizational change in Turkey. International Journal of Manpower, 29(5), 462-483. 
Elving, W. J. L. (2005). The role of communication in organizational change. Corporate Communication: An International Journal, 10(2), 129-138.

Facteau, J. D., Dobbins, G. H., Russell, J. E. A., Ladd, R. T. \& Kudisch, J. D. (1995). The influence of general perceptions of the training environment on pretraining motivation and perceived training transfer. Journal of Management, 21(1), 1-25.

Frahm, J. \& Brown, K. (2007). First steps: linking change communication to change receptivity. Journal of Organizational Change Management, 20(3), 370-387.

Gabriel, Y. (2000). Storytelling in organizations: Facts, fictions, and fantasies, Oxford University Press.

Gioia, D. A., Schultz, M. \& Corley, K. G. (2000). Organizational identity, image and adaptive instability. Academy of Management Review, 25(1), 63-81.

Howard, A. (2006). Positive and negative emotional attractors and intentional change. Journal of Management Development, 25(7), 657-670.

Inalhan, G. (2009). Attachments: The unrecognized link between employees and their workplace (in change management projects). Journal of corporate real estate, 11(1), 17-37.

Jones, E., Watson, B., Gardner, J. \& Gallois, C. (2004). Organizational communication: challenges for the new century. Journal of Communication, 54, 722-50.

Jimmieson N. L., Terry D. J. \& Callan V. J. (2004). A Longitudinal Study of Employee Adaptation to Organizational Change: The Role of Change-Related Information and Change-Related Self-Efficacy. Journal of Occupational Health Psychology, 9(1), 11-27.

Kanungo, R. N. (1982). Measurement of job and work involvement. Journal of Applied Psychology, 67(3), 341349.

Kohler, J. M., Munz D. C. \& Grawitch M. J. (2006). Test of a dynamic stress model for organizational change: Do males and females require different models? International Association of applied psychology.

Kirsch, C., Chelliah, J. \& Parry W. (2011). Drivers of change: a contemporary model. Journal of Business Strategy, 32(2), 13-20.

Mei, L. \& Hung, S. (2008). Research on how training influences administrative staff job involvement and organizational commitment. The Journal of Human Resource and Adult Learning, 4(2), 115-121.

Liao, C. S. \& Lee, C. W. (2009). An empirical study of employee job involvement and personality traits: The case of Taiwan. International Journal of Economics and Management, 3(1), 22-36.

Lewin, K. (1947). Frontiers in group dynamics: Concept, method and reality in social science; Social equilibria and social change. Human Relations, 1(1), 5-41.

Lodahl, T. M. \& Kejner, M. (1965). The definition and measurement of job involvement. Journal of Applied Psychology, 49, 24-33.

Milligan, J. M. (2003). Loss of site: organizational site moves as organizational deaths. International Journal of Sociology \& Social Policy, 23(6), 115-52.

Milligan, J. M. (1998). Interactional past and potential: the social construction of place attachment. Symbolic Interaction, 21(1), 1-33.

Noe, R. A. (1986).Trainees attributes and attitudes: neglected influences on training effectiveness. Academy of Management Review, 11(4), 36-49.

Noe, R. A, \& Schmitt, N. (1986). The influence of trainee attitudes on training effectiveness: test of a model. Personnel Psychology, 39, 497-523.

Proctor, T. \& Doukakis, I. (2003). Change management: the role of internal communication and employee development. Corporate Communication: an international journal, 8(4), 268-277.

Pettigrew, A. M., Woodman, R. W. \& Cameron, K. S. (2001). Studying organizational change and development: challenges for future research. Academy of Management Journal, 44(4), 697-713.

Randall, J. \& Procter, S. (2008). Ambiguity and ambivalence: Senior managements' accounts of organizational change in a restructured government department. Journal of Organizational change management, 21(6), 686-700.

Reichers, A. E., Wanous, P. J. \& Austin, J. T. (1997). Understanding and managing cynicism about organizational change. The Academy of Management Executive, 11(1), 48-59.

Shook, L. \& Roth, G. (2011). Downsizings, mergers and acquisitions: Perspectives of human resource development practitioners. Journal of European Industrial Training, 35(2), 135-153.

Suzy, F. (2001). Counterproductive work behavior (CWB) in response to job stressors and organizational justice: Some mediator and moderator tests for autonomy and emotions. Journal of Vocational 
Behavior, 59, 291-309.

Schalk, R., Campbell, J. W. \& Freese, C. (1998). Change and employee behavior. Leadership and Organization Development Journal, 19(3), 157-163.

Sommer, K. L. \& Baumeister, R. F. (1998). The construction of meaning from life events: empirical studies of personal narratives. The Human Quest for Meaning, 143-61, Mahwah, NJ: Erlbaum.

Taylor, J. R., Flanagin, A. J., Cheney, G. \& Seibold, D. R. (2001). Organizational communication research: key moments, central concerns, and future challenges in Gudykunst. Communication Yearbook, 24, 99137.

Uygur, A. \& Kilic, G. (2009). A study into organizational commitment and job involvement: An application towards the personnel in the central organization for Ministry of Health in Turky. Ozean Journal of Applied Sciences, 2(1), 113-125.

Vakola, M. \& Nikolaou, I. (2005). Attitudes towards organizational change: What is the role of employees stress and commitment? Employee Relations, 27(2), 160-174.

Wagner, E. (2008). Change beyond organizational transformation: Use of multipliers in change communication: How credible personal communication can make change effective. Springer-Verlag Berlin Heidelberg.

Weick, K. E. (2001). Making sense of the organization. Oxford University Press.

Weick, K. E. (1995). Sense making in organizations. CA: Sage Publications. 